\title{
Formação de professores da EJA para uso de TDIC no ensino e gestão: uma experiência da extensão universitária
}

\author{
Tenilson de Assis ${ }^{1}$, Jayanne Vieira Santos ${ }^{1}$, Jéssica Fernanda Silva Barbosa ${ }^{1}$, \\ Francys Rafael do Nascimento Martins ${ }^{1}$, André Almeida Silva ${ }^{1}$ \\ ${ }^{1}$ Universidade Federal de Alagoas (UFAL) - Unidade Educacional Penedo \\ Av. Beira Rio S/N, Centro - 57200-000 - Penedo - AL- Brasil \\ tenilsonassis@gmail.com, jaayvieiras@gmail.com \\ j.fernandabarbosalegmail.com, francys112008@hotmail.com, \\ andre.almeidaearapiraca.ufal.br
}

\begin{abstract}
The use of Digital Technologies of Information and Communication (TDIC) has been growing and arousing interest, especially in the education context. However, many educators still do not use them, leaving aside their benefits. This article presents experience reports related to the extension action "Possibilities of the use of Basic Informatics as a Teaching Tool for EJA teachers", which aimed to train teachers of the Youth and Adult Education program for the use of basic TDIC for teaching and management, increasing the possibilities of using the technologies already present in schools. The results show the importance of training and the fundamental role that the University has to contribute to society.

Resumo. O uso das Tecnologias Digitais de Informação e Comunicação (TDIC) tem sido crescente e despertando interesse, sobretudo, no contexto educação. Contudo, muitos educadores ainda não as utilizam, deixando de lado seus benefícios. Este artigo apresenta relatos de experiência referentes à ação de extensão "Possibilidades do uso da Informática Básica como Ferramenta de Ensino para professores da EJA”, que objetivou formar educadores do programa Educação de Jovens e Adultos para o uso de TDIC básicas voltadas ao ensino e à gestão, ampliando as possibilidades de uso das tecnologias já presentes nas escolas. Os resultados mostram a importância da formação realizada e o papel fundamental da Universidade como transformadora social.
\end{abstract}

\section{Introdução}

Os avanços das tecnologias e globalização criaram um mundo amplamente informatizado que, de forma nítida, é marcado pelo desenvolvimento nas áreas da comunicação e da informática, bem como ganhos advindos dos estudos científicos e tecnológicos. As tecnologias, especialmente, as Tecnologias Digitais de Informação e Comunicação (TDIC) estão cada vez mais inseridas no cotidiano das pessoas e nas mais diversas áreas de conhecimento. Logo, é importante conhecê-las e utilizá-las de forma adequada.

No campo da Educação, percebe-se grande possibilidade e relevância no uso das TDIC associadas ao processo de ensino e aprendizagem, além de questões inerentes à gestão das aulas e da escola como um todo, otimizando processos e despertando 
VIII Congresso Brasileiro de Informática na Educação (CBIE 2019)

Anais do XXV Workshop de Informática na Escola (WIE 2019)

profissionais da educação e estudantes no desenvolvimento de uma cultura digital direcionada a utilizar as tecnologias para ampliar e incrementar as formas de conceber e fazer a educação.

Nesta direção, a implantação de recursos tecnológicos no âmbito educacional tende a proporcionar uma melhor qualidade na educação, refletindo na maneira como as atividades são realizadas e no impacto delas na construção do conhecimento. Assim, as tecnologias na educação podem contribuir com o ensino, principalmente no acesso, organização e gestão dos conteúdos a serem ensinados/aprendidos [Mamede-Neves e Duarte 2008].

De fato, há grande potencial nesta união entre as TDIC e o campo educacional. Ressalta-se que a escola é um dos espaços que tem maior relevância social e o atual contexto tecno-educacional exige reformulações no processo de ensino e aprendizagem, voltadas não apenas à inserção das tecnologias digitais no ambiente escolar, mas, partindo de uma visão mais holística, pensando na integração dessas às políticas e práticas pedagógicas.

A fim de possibilitar o efetivo e adequado uso da TDIC nas escolas, os governos devem apoiar e incentivar a adoção de recursos digitais e equipamentos de informática, mesmo que básicos, nas instituições de ensino. Tanto as salas de aula poderão ser equipadas quanto proceder à criação de espaços próprios, como é o caso dos laboratórios de informática. Dessa forma, professores e estudantes usufruirão das tecnologias para gerar conhecimento e utilizá-lo para o seu cotidiano.

Outro ponto de destaque referente à adoção de recursos ou equipamentos digitais pelas escolas diz respeito a atualização e modernização da forma de facilitar o aprendizado, potencializando a geração do conhecimento através de estratégias que visam assimilar e incorporar a tecnologia com as propostas e plano de ensino, possibilitando aulas mais atrativas, dinâmicas e participativas, fato que colabora com todos os envolvidos na educação.

Assim, há fundamental importância na inserção das tecnologias na educação, facilitando o ensino e incluindo socialmente os indivíduos, promovendo ainda uma formação crítica dos alunos através do uso consciente e criativo das ferramentas computacionais [Boulic e Renault 1991; Muller et al 2016]. Essa formação facilita tanto o ensino em si quanto a gestão das aulas e das instituições, trazendo benefícios para todo o ambiente escolar.

Durante pesquisa inicial, realizada no contexto da ação de extensão "Possibilidades do uso da Informática Básica como Ferramenta de Ensino para professores da EJA", os educadores salientaram ser desafiador e, ao mesmo tempo, uma grande oportunidade inserir as TDIC no processo de ensino tradicional. Ao passo que elas ganham forma e espaço na escola, torna-se necessário que todos os atores da educação desenvolvam habilidades para adequarem-se a este "novo mundo". Logo, não bastaria apenas inserir recursos tecnológicos e pedagógicos modernos e sofisticados, mas prezar também pela formação relacionada a estas ferramentas.

Salienta-se que, para a sociedade, o cenário da extensão universitária é de grande importância e traz inúmeras contribuições, já que possibilita o contato dos acadêmicos com a comunidade em geral, executando na prática as teorias aprendidas em sala de aula. Assim, a extensão possui papel fundamental na vida de todos os atores 
VIII Congresso Brasileiro de Informática na Educação (CBIE 2019)

Anais do XXV Workshop de Informática na Escola (WIE 2019)

que compõem a Universidade, extrapolando os muros da instituição. É nesta direção que os estudantes analisam realidades e problemas sociais e que a população recebe o aprendizado, processo no qual todos se beneficiam, no que diz respeito ao desenvolvimento pessoal de cada ser, fato que gera profundas mudanças sociais [Rodrigues et al 2013].

Nesta percepção, ao fazer um breve estudo em uma escola de rede pública da cidade de Penedo/AL, vê-se que há a disponibilidade de materiais de informática, como computadores, caixas de som e projetores, porém alguns desses equipamentos estão em desuso, pelo fato de os educadores não saberem manuseá-los e, em alguns casos, apresentarem resistência quanto à utilização de Tecnologias Digitais de Informação e Comunicação nas atividades que há anos estão habituados a fazerem.

Dessa forma, o presente artigo visa discorrer sobre as experiências com a ação de extensão "Possibilidades do uso da Informática Básica como Ferramenta de Ensino para professores da EJA" que objetivou formar os educadores da modalidade de ensino Educação de Jovens e Adultos (EJA), abordando o uso de equipamentos periféricos básicos, bem como softwares livres e boas práticas de Internet, a fim de orientar quanto à informática na educação. Com os resultados, evidenciou-se a importância dessa formação na realidade dos participantes e o papel fundamental que a Universidade possui como transformadora social.

\section{Materiais e Métodos}

A ação de extensão aqui apresentada foi realizada no primeiro semestre de 2019 na Universidade Federal de Alagoas - Unidade Educacional Penedo (UE Penedo), contando com uma equipe executora composta por 02 (dois) docentes dessa instituição, na qualidade de orientadores, e por um grupo de 09 (nove) estudantes colaboradores, composto por membros do Programa de Educação Tutorial Conexões do Saberes, bolsistas e alunos do curso de Sistemas de Informação, previamente selecionados para auxiliar no cumprimento das atividades.

A princípio, buscou-se definir um cronograma composto por etapas, a fim de sistematizar e melhor organizar o passo a passo para a obtenção do resultado pretendido, qual seja: educadores do programa Educação de Jovens e Adultos para o uso de TDIC básicas voltadas ao ensino e à gestão. Dessa forma, a execução foi idealizada em 06 (seis) momentos: i) pesquisa de escolas com aulas da EJA e seus recursos audiovisuais disponíveis; ii) reunião com a direção das escolas e Secretaria de Educação, a fim de divulgar e alinhar o projeto; iii) definição da data de realização da formação e inscrição dos professores/participantes; iv) orientação dos discentes envolvidos no projeto acerca da forma e conteúdo a ser ministrado; v) realização da formação dos participantes (professores inscritos); e vi) aplicação de questionário para identificar o aprendizado posterior à formação [Silva et al 2018].

Inicialmente, a equipe executora partiu para pesquisa de campo, observando as escolas da cidade de Penedo, no estado de Alagoas, localidade na qual a Universidade está localizada e onde os membros da ação residem. Percebeu-se que a Escola Municipal de Educação Básica Vereador Manoel Soares de Melo é o polo da EJA na cidade, contando com cerca de 230 (duzentos e trinta) estudantes, 14 (quatorze) professores, dispostos em 06 (seis) turmas. Foi visto que essa escola possui projetores multimídia e caixas de som, contanto também dez computadores organizados em um 
VIII Congresso Brasileiro de Informática na Educação (CBIE 2019)

Anais do XXV Workshop de Informática na Escola (WIE 2019)

laboratório de informática. Logo, por conta do número de indivíduos ligados à EJA e pela escola possuir equipamentos básicos relacionados às TDIC, após reunião com a direção e Secretaria de Educação, a destacada escola foi escolhida para a ação de extensão "Possibilidades do uso da Informática Básica como Ferramenta de Ensino para professores da EJA".

Em seguida, procedeu-se à apresentação das atividades aos professores, buscando identificar suas carências e necessidades em relação ao uso das TDIC na educação. Neste ponto foi aplicado um questionário para que os educadores relatassem dificuldades e intenções acerca da utilização dos equipamentos e softwares básicos de informática que a escola possui. A maioria das respostas relataram problemas de atividades consideradas básicas, como baixar vídeos da internet, pesquisar conteúdos educacionais em sites confiáveis, imprimir provas e documentos diversos, dentre outras ações que, para muitos, são rotineiras e consideravelmente simples.

Com base nas respostas desses questionários definiu-se o conteúdo a ser ministrado e a metodologia utilizada na formação, sendo o conteúdo: breve história do computador; explorador de arquivos e equipamentos; usos da Internet; LibreOffice Impress; LibreOffice Writer e LibreOffice Calc. A metodologia baseou-se em aulas teórico-práticas, com o uso dos mesmos meios computacionais que os participantes poderão utilizar em seus trabalhos, guiadas por apostila contendo todos os assuntos referenciados e exercícios de fixação que foi desenvolvida, impressa e entregue aos participantes da formação, com intuito de eles terem um material físico de consulta para auxiliar no aprendizado.

Após essas etapas, ocorreu a capacitação realizada presencialmente no laboratório de informática da Universidade Federal de Alagoas, Unidade Educacional Penedo, composto por 20 (vinte) computadores e aparelho de projeção e reprodução de som. Foi definido, em reunião com os professores participantes, que as aulas teriam duração de quatro horas e seriam, inicialmente, ministradas em 08 (oito) sábados, podendo ser estendidas caso houvesse necessidade. Os temas das aulas foram divididos entre os membros da equipe executora que atuaram como facilitadores e monitores, ou seja, ministrando os conteúdos e auxiliando os participantes diante de dúvidas e exercícios.

Salienta-se que o uso das tecnologias nas instituições educacionais deve frisar a inclusão de todos os indivíduos ligados à escola e ser norteado pela qualidade para a formulação de metodologias de ensino e aprendizagem otimizadas e adequadas à realidade atual. Neste direcionamento, é visto que a importância da utilização de TDIC na área educacional é indiscutível e necessária, pensada diante do aspecto pedagógico e social. O papel da escola ultrapassa o da formação em capacidades baseadas da mera valorização da memorização. Surge um novo conceito de inteligência que traz o computador como facilitador no desenvolvimento de habilidades lógico-matemática, linguística, interpessoal, intrapessoal, espacial, musical, corpo-cinestésica, naturista e pictórica [Tajra 2000].

Finalizada a capacitação, foi aplicado questionário idêntico ao primeiro, com a finalidade de verificar o aprendizado dos inscritos e observar se as necessidades iniciais haviam sido atendidas. A partir das respostas é possível inferir os resultados da ação de extensão realizada, trazendo importante feedback para trabalhos futuros associados às atividades realizadas. 
VIII Congresso Brasileiro de Informática na Educação (CBIE 2019)

Anais do XXV Workshop de Informática na Escola (WIE 2019)

\section{Resultados e Discussão}

Após analisar os questionários aplicados no início da ação, referentes ao conhecimento prévio de cada professor acerca do uso de TDIC para planejamento e execução de aulas, as respostas mostraram que a maioria já havia utilizado computadores em suas casas e ambiente de trabalho e, inclusive, já fizeram cursos de informática básica. Porém, o uso ferramentas computacionais aliadas às questões de ensino era limitada.

Diante deste cenário, a apostila desenvolvida e citada na seção anterior buscou abarcar todo o embasamento inicial, rememorando conceitos básicos de informática, demonstrado de forma ilustrada e intuitiva a utilização de computadores e tecnologias associadas, para então partir para demonstrações das possibilidades pedagógicas advindas da associação TDIC e Educação.

No decorrer das aulas presenciais, os professores participantes viram de forma breve a história e evolução dos computadores e conheceram as partes principais e funcionamento básico dessas máquinas, assim como viram de forma mais detalhada o uso e instalação de equipamentos periféricos, como impressoras e projetor multimídia. $\mathrm{Na}$ sequência participaram de exercícios para o uso adequado dos acessórios do computador, como o mouse e teclado, explorando atalhos e modos ergonômicos de utilização. Quando solicitada digitação de texto, observou-se certa aptidão à tarefa, com boas velocidade e qualidade, porém, foi notória a dificuldade com o uso de letras maiúsculas, segunda e terceira função das teclas de pontuação e símbolos.

A formação enfatizou os softwares do LibreOffice, suíte de aplicativos livre para escritório, focando naqueles que são usualmente mais utilizados: Writer (editor de texto), Calc (planilha eletrônica) e Impress (apresentador de slides). No primeiro foi possível indicar e destacar como exercícios, avaliações e trabalhos podem ser redigidos facilmente, bem como as formas de torná-los mais atrativos através técnicas de formação e edição. No segundo fora demonstrada as possibilidades e facilidades do trabalho de gestão apoiado com planilhas, mostrando a aplicação de fórmulas e funções, além do gerenciamento de notas e outros aspectos. No último software mostrou-se como as aulas podem ficar mais fluidas e melhorar a assimilação dos alunos através do uso de slides no projetor multimídia

Levando em consideração o atual estágio de importância das redes de computadores e sua utilização como forma de adquirir informação e construir conhecimento, fomentada pelo uso das TDIC, foi apresentado o uso da Internet voltado à busca de referências de conteúdo a serem levados à sala de aula, objetivando consegui-los da forma mais atualizada possível, fazendo com os alunos e professores não se limitem apenas ao uso de livros didáticos e meios físicos que já não são vistos como as únicas referências ou fontes de consulta e, em muitos casos, podem conter dados ultrapassados.

Esse direcionamento se dá pela lógica que reforça a ideia de que a escola precisa repensar suas concepções de ensino/aprendizagem, afastando a verdade, muitas vezes absoluta e inquestionável, que apenas o livro e ela própria se configuram como únicas possibilidades de aquisição de conhecimento e de cultura. Deve-se, portanto, partir para outra direção e pensar em outras concepções, nas quais conhecimento, cultura e comunicação se aproximam, observando o processo de ensino e aprendizagem formal diante dos novos parâmetros teórico/conceituais [Mamede-Neves e Duarte 2008]. 
VIII Congresso Brasileiro de Informática na Educação (CBIE 2019)

Anais do XXV Workshop de Informática na Escola (WIE 2019)

É importante mencionar que, mesmo após a formação, muitos dos profissionais ainda encontrarão dificuldade para colocar em prática aquilo que se aprendeu durante as aulas da ação, pois, quando existentes, os laboratórios de informática das escolas são insuficientes ou sucateados, tornando a tarefa de usar ferramentas computacionais no processo de ensino cada vez mais árdua. Logo, é importante focar nas estratégias de utilização das tecnologias diante da atuação dos professores em sala de aula, buscando minimizar os problemas de falta de máquinas, tendo em vista que as turmas, em regra, superam os 40 (quarenta) alunos e que as escolas não foram projetadas, inicialmente, para destinar um espaço próprio ao uso da informática [Costa e Almeida 2012].

A Figura 1 e a Figura 2 mostram dois momentos da formação, na qual os participantes tiveram aulas sobre a história e evolução dos computadores, conheceram a instalação básica de periféricos e utilização dos aplicativos de escritório.

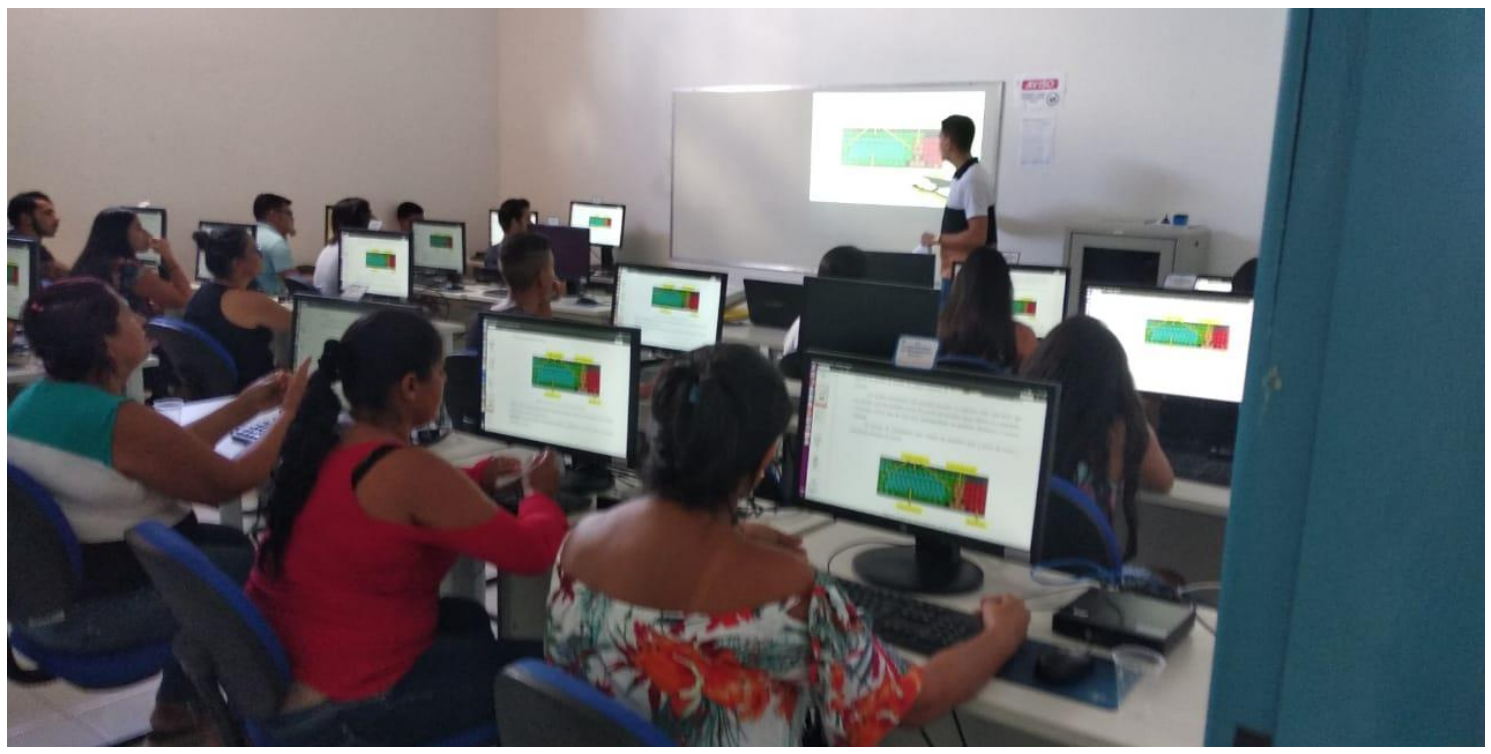

Figura 1. Formação dos participantes da ação: aula sobre periféricos.

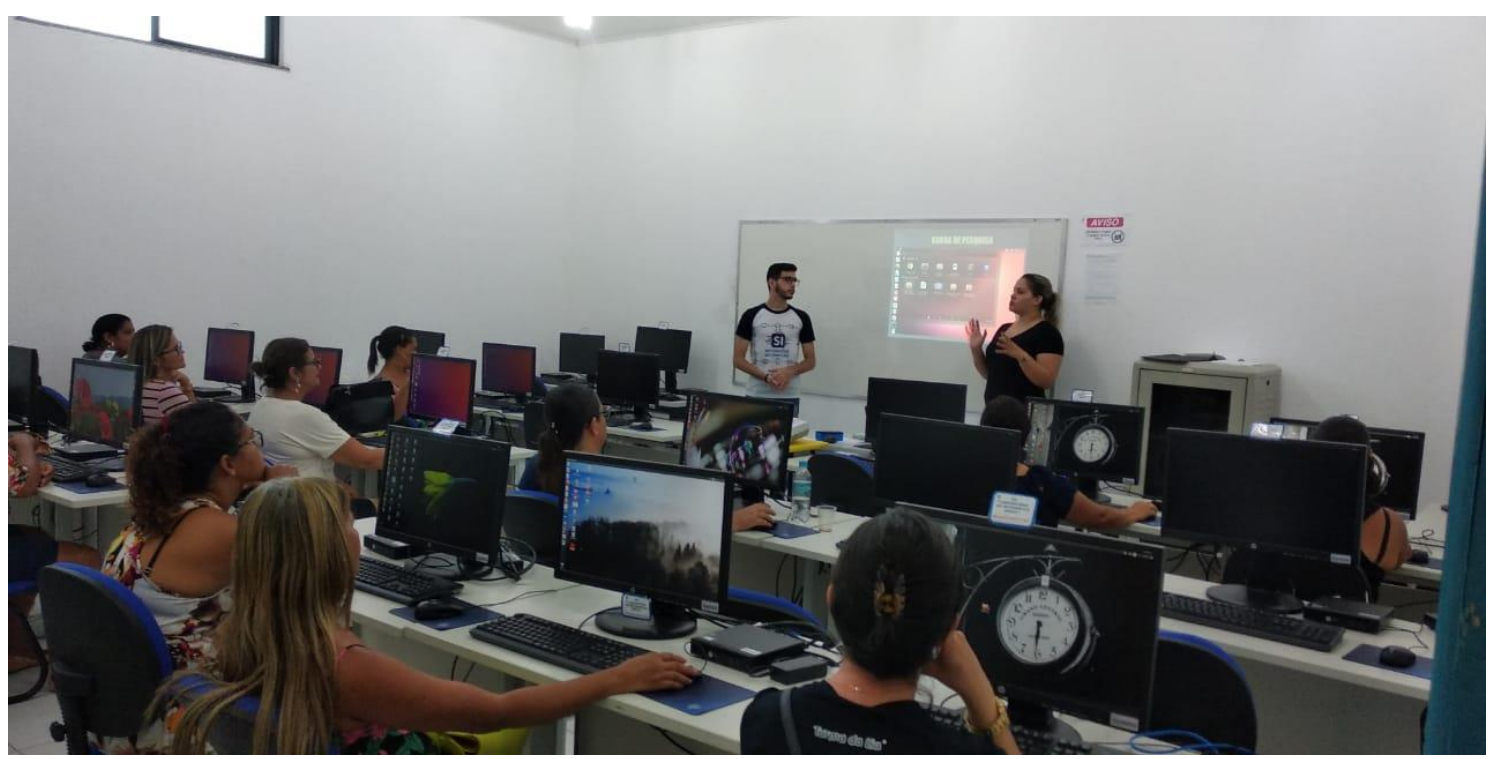

Figura 2. Formação dos participantes da ação: aula sobre o funcionamento do computador. 
VIII Congresso Brasileiro de Informática na Educação (CBIE 2019)

Anais do XXV Workshop de Informática na Escola (WIE 2019)

Sabe-se que outro ponto a ser considerado é a resistência dos professores quanto ao uso das ferramentas computacionais na Educação. Alguns trazem como justificativa a essa questão a falta de recursos adequados, como laboratórios equipados para que a prática possa existir [Odorico et al. 2012]. Assim, a ausência de estrutura acarreta na reprodução de uma mesma metodologia dissociada ao uso de TDIC na educação, permanecendo as dificuldades para preparar e executar aulas com maior potencial de atração e inclusão.

Destaca-se que, ao final das aulas, com a reaplicação do questionário inicial, ficou notável um incremento na autoavaliação referente aos conhecimentos em TDIC, isto é, as dificuldades relatadas no início, como aspectos de utilização da Internet para fins educacionais e formatação de textos, foram reduzidas. Com os resultados podem ser concebidos trabalhos futuros, otimizando os conteúdos ministrados e pensando em novos públicos.

A seguir serão apresentados três comentários de professores da EJA, participantes da ação de extensão discorrida neste artigo, acerca da formação realizada. Eles não quiseram se identificar, mas autorizaram a publicação de seus depoimentos que são importantes para aferir o posicionamento em relação às atividades realizadas.

"As aulas de informática sempre serão importantes na vida pedagógica. Os avanços tecnológicos obrigam a nossa carreira praticar o uso desses recursos. O grande problema, são as oportunidades e o custo desses cursos. Hoje, com a possibilidade da oferta gratuita Federal, agradecemos e queremos outras oportunidades".

"As aulas foram importantes para o desenvolvimento tecnológico, visto que devemos acompanhar as novas ferramentas para o desenvolvimento de nossos alunos. Além de facilitar nosso trabalho".

"Foi importante por que adquiri muito conhecimento, pois não conhecia muitas dessas ferramentas. Vai contribuir muito pois aprendi a fazer atividades e a colar figuras. Antes de fazer esse curso, eu dependia dos meus filhos para colar figuras".

Em suma, a ação realizada buscou formar os educadores quanto à utilização das tecnologias básicas de informática, oportunizando aos professores da EJA uma ampliação do olhar voltado à adoção de TDIC como fomentadora do processo de ensino e aprendizagem. Ressalta-se que essa ação faz parte de um projeto de extensão desenvolvidos por docentes e discentes da UFAL/UE Penedo, fato que destaca o importante papel social que a Universidade têm, indo além dos seus muros e contribuindo com as demandas da sociedade.

\section{Conclusão}

A ação de extensão "Possibilidades do uso da Informática Básica como Ferramenta de Ensino para professores da EJA" trouxe importantes contribuições para todos os nela envolvidos, sendo basilar o engajamento ocorrido entre docentes e discentes na execução dos 06 (seis) momentos organizados para atingir o objetivo pretendido, iniciados pela pesquisa de escolas com aulas da EJA, passando pela análise das necessidades do público e formação e finalizando com a mensuração das atividades realizadas. 
VIII Congresso Brasileiro de Informática na Educação (CBIE 2019)

Anais do XXV Workshop de Informática na Escola (WIE 2019)

Sobre a participação dos professores da EJA na formação realizada, através de aulas teórico-práticas e participativas na UFAL/UE Penedo, viu-se grande carência em relação ao uso do computador para tarefas inerentes à escola. Mesmo com certo domínio em informática básica, as possibilidades pedagógicas ou de gestão de turmas não eram exploradas pelos educadores, limitando tanto a concepção quanto a execução das aulas que eles lecionam. Assim, foram oferecidas formas, guiadas às TDIC, de enxergar e realizar as tarefas do cotidiano pessoal e escolar, desenvolvendo uma nova mentalidade que distancia o receio de utilizar tecnologias na educação.

Acrescenta-se que a ação de extensão aqui apresentada impacta também, pessoal e profissionalmente, na vida dos estudantes que a executaram. É dessa forma que a Universidade cumpre a sua função estruturada no tripé ensino-pesquisa-extensão, formando sujeitos capazes contribuir com a sociedade e idealizando ações para a melhoria dos problemas identificados no seu contexto social. Além disso, desenvolve-se capacidades cognitivas que contribuirão para uma formação completa.

De fato, nota-se que uso da tecnologia está cada vez mais frequente na educação, tornando ainda mais necessário o estudo da influência das TDIC e formação de recursos humanos para aliá-las aos processos de ensino e aprendizagem. Assim é necessária e urgente pensar na formação continuada de educadores para o emprego adequado dessas tecnologias, tornando-as ferramentas de ensino. Pretende-se dar continuidade à ação de extensão aqui discorrida, abrangendo mais escolas e novos participantes, contribuindo para a otimização do ensino das escolas da região e da educação pública, como um todo.

\section{Referências}

Boulic, R. and Renault, O. (1991) "3D Hierarchies for Animation”, In: New Trends in Animation and Visualization, Edited by Nadia Magnenat-Thalmann and Daniel Thalmann, John Wiley \& Sons ltd., England.

Costa, A. L. M., Almeida, F. J. (2012) Condições materiais e a eficácia da informática aplicada à educação: a culpa é do professor?, I Congresso Brasileiro de Informática na Educação (CBIE 2012). Anais do XVIII Workshop de Informática na Escola. Rio de Janeiro, RJ. 2012.

Mamede-Neves, M. A. C., Duarte, R. (2008) "O contexto dos novos recursos tecnológicos de informação e comunicação e a escola", In: Educação e Sociedade, vol. 29, n. 104 - Especial, p. 769-789, out. 2008, Campinas. Disponível em: http://www.scielo.br/pdf/es/v29n104/a0729104. Acesso: maio 2019.

Muller, E. E. R. et al. (2016) A importância dos recursos digitais no ambiente escolar. Disponível em: https://repositorio.ufsc.br/bitstream/handle/123456789/167480/TCC\%20Muller.pdf? sequence=1\&isAllowed=y. Acesso: maio. 2019.

Odorico, K. E., Nunes D. M., Moreira A., de Oliveira H. M. P., Cardoso A. (2012) Análise do Não Uso do Laboratório de Informática nas Escolas Públicas e Estudo de Caso. I Congresso Brasileiro de Informática na Educação (CBIE 2012). Anais do XVIII Workshop de Informática na Escola. Rio de Janeiro, RJ. 2012.

Rodrigues, A. L. L., Do Amaral Costa, C. L. N., Prata, M. S, Batalha, T. B. S., Neto, I. D. F. P. (2013) Contribuições da extensão universitária na sociedade. Cadernos de Graduação - Ciências Humanas e Sociais - UNIT, v.1, n.16, p.141-148, 2013. 
VIII Congresso Brasileiro de Informática na Educação (CBIE 2019)

Anais do XXV Workshop de Informática na Escola (WIE 2019)

Silva, A. A., Nunes, A. C., Barbosa, J. F. S., Garcia, L. L. O., Santos, L. S., Albuquerque, N. L. B., De Assis, T. (2018) Informática Aplicada à Educação Básica nas Escolas Públicas: Formação de Educadores de Penedo/AL para o Uso das TDIC. VII Congresso Brasileiro de Informática na Educação (CBIE 2018). Anais do XXIV Workshop de Informática na Escola (WIE 2018).

Tajra, S. (2000) "Informática na educação: novas ferramentas pedagógicas para o professor da atualidade", 2. ed. São Paulo: Érica. 